\title{
CARBON DIOXIDE EMISSION FROM DIESEL ENGINE VEHICLES IN INTERMODAL TRANSPORT
}

\author{
Mariusz BRZEZIŃSKI, Dariusz PYZA \\ Faculty of Transport, Warsaw University of Technology, Warsaw, Poland \\ Submitted 25 August 2020; resubmitted 11 February 2021; accepted 20 April 2021
}

\begin{abstract}
Currently, many logistics operators operate in both domestic and foreign markets using various forms of transport organization. Choosing a corresponding technology and appropriate form of transport has an influence not only delivery time and costs, but also has an impact on the environment as a whole. There is a plethora of public research available in global literature discussing various ways of exploiting transport. On the other hand, there is a lack of complex studies detailing carbon emissions coming from transport activity. Specifically, where a theory of organic fuel combustion in the form of a chemical reaction with oxygen is considered. To fill this gap, we offer an innovative Emission Model of Industrial Sources (EMIS) method. This method makes it possible to determine the amount of $\mathrm{CO}_{2}$ emitted into the atmosphere during various transport methods. It also enables us to estimate, in terms of $\mathrm{CO}_{2}$ output, a threshold where transport of containers via combined mode becomes more favourable for the environment, than road transport. We ran a simulation of our algorithm to create boundary conditions. This let us prepare a regression function of $\mathrm{CO}_{2}$ emission, for intermodal and road transport as a function of various transport distances. The simulation results suggest that our approach may be used by supervisory institutions, which are responsible further developing and utilizing combined transport.
\end{abstract}

Keywords: intermodal transport, carbon dioxide, environment, sustainable transport, transport emissions.

\section{Notations}

$$
\begin{gathered}
\mathrm{CO}_{2} \text { - carbon dioxide; } \\
\mathrm{EMIS} \text { - emission model of industrial sources; } \\
\mathrm{g} \mathrm{CO}_{2} / \mathrm{g}-\mathrm{t}-\mathrm{km} \text { - gram } \mathrm{CO}_{2} \text { per gross-tone-kilometre; } \\
\mathrm{GHG} \text { - greenhouse gas; } \\
\mathrm{H}_{2} \mathrm{O} \text { - steam; } \\
\mathrm{HGV} \text { - heavy goods vehicle; } \\
\mathrm{N}_{2} \text { - nitrogen; } \\
\mathrm{VBA} \text { - Visual Basic for applications. }
\end{gathered}
$$

\section{Introduction}

Presently, global economic development determines the growing flow of cargo and passengers. In this regard, sustainable transport becomes more and more important for social life. Sustainable transport can be defined as, all activities having an influence on the safety and ecology of transport. In doing so, all elements of sustainable transport should be planned in a manner, which permits peak effectiveness in terms of the economic, social and ecologic aspect of transport systems. Thus, sustainable transport must be environmentally friendly, energy efficient and safe for the community, no matter, which transport branch is considered (Ambroziak et al. 2013; MTBGM 2013). Additionally, sustainable transport must use efficient forms of transport as well as alternative sources of engine propulsion. In the scope of cargo transport, hope for the future of transport consists of development of high speed rail an inclusive intermodal transport branch (Jacyna et al. 2017).

Accordingly, in our research, we would like to emphasize how organization of the transport process can cause growth or reduction of GHG emission. For example, we compared carbon emissions resulting from intermodal and road transport. During the process, certain groups of parameters related to transport organization were tested. It enabled us to follow the characteristics of $\mathrm{CO}_{2}$ emission deriving from the process of diesel fuel incineration, which takes place in locomotive engines and HGV.

For scientific purposes, we conducted an extensive literature review on the topic of intermodal transport network modelling, and the issue of volatile compounds emitted during the process of fuel combustion. This step was necessary to broaden our understanding of the field.

${ }^{*}$ Corresponding author. E-mail: mbrze94vp@gmail.com 
We also decided to adopt elements and schemes of intermodal transport network modelling derived from numerous available materials. However, as it turned out, current literature lacks a clear and complete numerical attitude to the calculation of carbon emission. Typically, experts analyse data that is already retrieved from available programs, found on the internet. In contrast, we decided to present a unique approach to this topic and design the EMIS method. Based on the EMIS method we prepared our own program that enabled us to run our simulation instead of using other programs. Most importantly, we used a notion of container triangulation, which is commonly used in practical logistics. This step helped us simulate real world conditions taking place in the logistical world. It is worth noting, that this method contains not only the elements of transport process modelling, but in addition, uses a simplified theory of organic fuel combustion, which is novelty in the field of the logistics papers.

This paper is organized as follows:

"» section 1 reviews crucial literature about the current role of intermodal transport, empty container reuse and intermodal transport network modelling;

"» section 2 presents assumptions of the model and EMIS method, which enables us to estimate $\mathrm{CO}_{2}$ output in road and intermodal transport;

"» section 3 reports simulation results;

»» section 4 discusses the paper concludes and analyses.

\section{Literature review}

\subsection{Role of intermodal transport}

Intermodal transport is a subset of transport where cargo is transported in the same loading units from consignor to consignee with the use of the subsequent branches of transport. Usually, the arrangement of the intermodal transport process determines the usage of combined transport. Combined transport is also a branch of intermodal transport, but here the vast majority of transported distance is accomplished by rail, inland navigation or sea shipping. Pre-carriage and on-carriage distance is proceeded by road transport (Ambroziak et al. 2014). Loading and unloading points are identified as intermodal terminals and together, with transport connections, form an intermodal transport network (Figure 1).

A structure of the transport network results from the type and volume of transport tasks, manner of transport organization as well as the number and specification of customers.

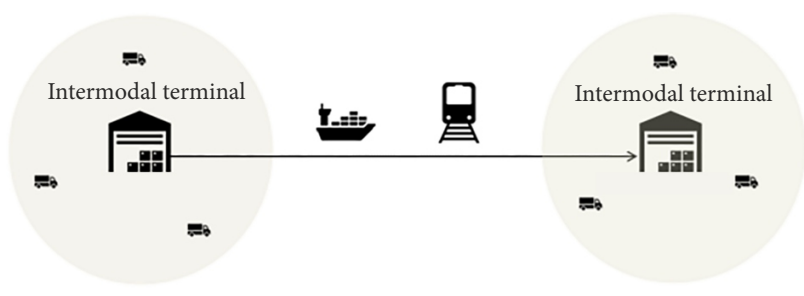

Figure 1. Scheme of container flow between intermodal terminals
A growing amount of cargo and passengers determine the dynamic transport development that entails environmental and social costs. Meaning, transport development has a very destructive influence on the natural habitat creating significant external costs, triggered by: harmful exhausts, noise and traffic accidents (Ambroziak et al. 2013). There is an urgent need to curb its influence on human life and the environment. Currently, the most important step is to improve the competitiveness of the railway sector and increase the share of rail and inland navigation transport in the market. On the other hand, there is a need to curb the share of HGV transport in the market. It is worth noting that this type of transport is the dominant mode in the entire European Union. This phenomenon entails a substantially negative implication. Road transport is widely perceived as the most invasive human activity, damaging the natural habitat. The fuel combustion process in a vehicle engine, releases many volatile and mechanical molecules into the atmosphere, some less harmful than others. It is worth noting that the consistency of the air pollution depends on several factors. Distinguishable, among others by; type and characteristics of vehicles, fuel type, infrastructure location, vehicle velocity and trafficjam origin place (Pyza 2019).

Accordingly, in these findings we present recipe to reduce the environmental impact of HGV transport mode.

\subsection{Triangulation it means "empty container reUSE"}

A notion of triangulation has been introduced to better understand the road and intermodal process of deliveries. Triangulation is a process that allows more efficient use of vehicles. Usually, an unloaded container at a recipient's location is redirected as empty to the next customer, where a container is reused for goods loading. Meanwhile, a driver does not have to go back to the terminal. Thus triangulation mitigates the financial impact on the budget of transport companies. In addition, the triangulation reduces $\mathrm{CO}_{2}$ emission because it limits the vehicle's empty courses. Furthermore, this step enables relative theoretical research and a practical aspect of transport organization. Generally, a notion of triangulation is used in the jargon of the biggest container companies such as Maersk, MSC and also companies supporting intermodal business like Avantida (https://platform.avantida.com). In literature, the notion of triangulation is defined as "empty container reuse". This process has been quite precisely described by Jula et al. (2006). Experts adopted this method to minimize empty vehicle courses and road congestion within the range of the Los Angeles/Long Beach seaport (US). Similarly, our papers also showed an analytic model, which included a case study based on current and future demand for container transport. This appliance enabled experts to assess the solution in an impartial way. It turned out, that triangulation brings rational savings within the scope of an enterprise's financial budget. Accordingly, in our studies we will prove that such a solution will also have an impact 
on our natural habitat and will help decrease negative influence thanks to a diminished number of HGV courses. More broadly, the application of triangulation has been described by Belmecheri et al. (2009). The difference was, that in this case, costs were optimized by limiting empty vehicles transferring from the port terminal to the depot, from recipients to depots and from depots to shippers. In addition, the model was impacted by certain limitations, i.e. shippers could only obtain containers from consignees and depots could only store containers used in triangulation. Here, in order to resolve the optimization problem, a Solver embedded in the packet of Microsoft Excel has been applied. A similar tool has been used in our case study.

Presently, many enterprises around the world whose main area of activity is container turnover, analyse their supply chain. These enterprises focus primarily on environment issues and cost optimization. Experts noticed that container triangulation perfectly reflect the policy of the green logistics chain. In their analysis, the volume of container flow and their weights have been taken into account, which was convergent with the subject of our research. The most complex studies about container reuse were carried out in position of Boile (2006). Scientist considered container repositioning from a local, regional and global point of view. Primarily, the highest pressure has been put on the regional and local sphere where it has been demonstrated and all model limitations have been analysed. A crucial issue was to figure out what kind of profit can be brought from the decision-making system regarding empty container transfers. The final effect was growth of supply chain effectiveness, by reducing the number of stored empty vehicles and limiting their transfer between depots and consignees or consignors. Similarly, we also considered the influence of triangulation on a local scale as well as the added value from implementation of the triangulation process.

\subsection{Aspect of intermodal network modelling in terms of environmental impact}

Today, the rapidly developing technology of intermodal transport involves tackling complex solutions in the scope of transport and loading operations in intermodal terminals. Environmental contamination has changed the approach of logistic operators who nowadays are reaching cargo flow consolidation by increasing means of transport utilization. Experts (Fan et al. 2019) have identified three types of cargo consolidation: (1) non-consolidated flow, (2) container-consolidated and (3) combined-consolidated. In this paper, researches assessed a distinct method of container flow on its economic effectiveness as well as impact on the environment. Each of these models were evaluated on the basis of total costs and total carbon emissions. Heggen et al. (2019) described the issue of container delivery from/to intermodal terminals. Focus was placed on the short- and long-distance routing issue between intermodal terminals in cases where regions contained multiple terminals. This attitude reduces the total number of kilometres transported, because of more effective utilization of transport connections. In this case, the driver's working time, scheduling, and cut-off time were considered.

The issue of intermodal network modelling and its environmental impact has been a widely recognized subject by many researchers in global literature. Many analyses have been conducted in this field. Those analyses concerned among others:

"» intermodal transport effectiveness (Monios, Bergqvist 2017; Santos et al. 2015; Wiegmans, Konings 2015);

"» handling process optimization (Boysen, Fliedner 2010; Cordeau et al. 2015; Fedtke, Boysen 2017; Guo et al. 2018);

"» studies about intermodal carriages both in Poland and in the world (Flodén, Woxenius 2017; Grzelakowski 2012; Saeedi et al. 2017);

"» empty intermodal transport units management (Furió et al. 2013; Hjortnaes et al. 2017);

"» localizations of the intermodal terminals (Limbourg, Jourquin 2009; Lin et al. 2014; Brzeziński, Pyza 2020);

"» environmental impact of intermodal transport (Arnold et al. 2004; Braekers et al. 2009; Craig et al. 2013; Dimoula et al. 2016; García-Álvarez et al. 2013; Hjortnaes et al. 2017; Jacyna et al. 2017; Kreutzberger et al. 2006; Li et al. 2013, 2014; LópezNavarro 2014; Monios, Bergqvist 2017; EC 2015; Ritchie, Roser 2017; Southworth, Peterson 2000).

However, current literature lacks reliable case studies showing a connection between the aspect of intermodal network modelling and GHG emission. To fill this gap we offer the EMIS method, which presents our individual attitude towards this issue.

\section{Materials and methods}

\subsection{Literature background for EMIS method}

This method was elaborated based on the author's empirical experience. Of course, in literature there are a lot of papers that have an akin attitude to $\mathrm{CO}_{2}$ emission. For instance, in position (Lebedevas et al. 2017) demonstrated results, in the same manner as our work, coming from mathematic modelling within the field of freight rail transport. But in this case however, experts focused on researching how much fuel and energy is consumed by diesel locomotive freight, or how much $\mathrm{CO}_{2}$ is emitted when moving on the main rail track of Lithuania. Researchers proposed a series of special solutions. In order to assess, which solution is optimal, they used certain criteria. Contrary to our papers, they have also considered another volatile compound. In their case study $\mathrm{CO}_{2}$ emission levels were dependent on the total weight of the train. Experts considered this weight to be between $3000 \ldots 7500 \mathrm{t}$. In our consideration, the train was much lighter. Besides, they obtained results based on a computer simulation. For 
example, we built our method and program from scratch. In the next source (Rajkovic et al. 2016), carbon emission was completely dependent on cargo weight and cargo volume, which, from our point of view wasn't justified. In our model, for instance, another factor was taken into account - tare of wagons that was a component of total train weight. Therefore, researchers calculated $\mathrm{CO}_{2}$ emission as a $\left[\mathrm{g} \mathrm{CO}_{2} / \mathrm{t}\right.$-cargo]. Instead, we calculated carbon emission as a $\left[\mathrm{g} \mathrm{CO}_{2} / \mathrm{t}-\mathrm{km}\right]$. However, they created their own method and designed it in the MATLAB. We did the same, but we used VBA language and Microsoft Excel. On the other hand, they presented a wider attitude to carbon emission because they also considered carbon emission deriving from sea transport. A very innovative result is showed by García-Álvarez et al. (2013). However, in this paper only electric locomotives were taken into consideration. Experts designed a model where lost power played a key role. As a result, they received $\mathrm{CO}_{2}$ emission calculated per $[\mathrm{kW} \cdot \mathrm{h} / \mathrm{t}-\mathrm{km}]$. Our method does not include research on electric locomotives but it will definitely become a topic of our future papers.

\subsection{General methodology assumptions}

To test transport emissions in the EMIS method, a comparative analyses must be carried out. The analysis mainly concerns the field of goods carriage by road and intermodal transport. $\mathrm{CO}_{2}$ emitted by road and intermodal transport has been chosen as a criteria of negative impact on the natural habitat. To conduct the research authors of this paper must: (1) formulate the assumptions concerning the scope of process transport organizations, (2) carry out the parameterization of the input data, which characterizes the transport process, (3) describe a method and level of carbon emission, (4) prepare a simulation for the chosen input parameters.

A full code of conduct during the process of this researching depicts the Figure 2.

A simplified container delivery sequence has been presented below:

1) for intermodal transport:

"» empty containers are provided to the consignor's location, where loading takes place. A number of empties and their structure is perceived as a function of demand. Empty containers are provided, both from the unknown consignee under the process of triangulation, as well as directly from the intermodal terminal. Designation $\beta_{1}$ means, a share of empty containers provided to the consignor from the random consignees. Other parts of containers that are picked up from the terminal are marked as $\beta_{2}=1-\beta_{1}$, where $\beta_{1} \wedge \beta_{2} \in\langle 0,1\rangle$;

"» the empty container is loaded in the consignor's location. Then, the unit is delivered to the intermodal terminal $B_{w}$ as a full unit;

"» a group of full containers are loaded onto the train, then carried to another intermodal terminal $E_{w}$;

"» containers are reloaded from the train onto trucks and delivered to the final consignees;

"» containers are unloaded at the consignee's location Then, empty units return to the terminal or are being provided to another consignor's points in order for reuse. Designation $\beta_{3}$ denotes a share of empty containers that are provided to another consignor from the unloading point. Other parts of containers that return as empty to the terminal are marked as $\beta_{4}=1-\beta_{3}$, where $\beta_{3} \wedge \beta_{4} \in\langle 0,1\rangle$.

2) for road transport:

"») empty containers are provided to the consignor's location, where loading takes place. Similarly, a number of empties and their structure is perceived as a function of demand. Empty containers are provided both from the unknown consignees under the process of triangulation as well as directly from the pickup/drop-off point marked as $D_{w}$. Designation $\theta_{1}$ is a share of empty containers that are provided to consignor from the unknown consignees. Another part of containers that are picked up from the pickup/ drop-off point is marked as $\theta_{2}=1-\theta_{1}$, where $\theta_{1} \wedge \theta_{2} \in\langle 0,1\rangle$;

»» empty containers are loaded and carried directly to consignees as a full unit;

"» containers are unloaded at the consignee localization. Then returned to the pick up/drop-off point or are provided to another consignor for reuse. Designation $\theta_{3}$ denotes a share of empty containers that are provided to another consignor from the unloading point. Other parts of containers that return as empty to the pickup/ drop-off point are marked as $\theta_{4}=1-\theta_{3}$, where $\theta_{3} \wedge \theta_{4} \in\langle 0,1\rangle$ and $\theta_{3}=\theta_{1}$.

In the case of door-to-door deliveries, the values of parameters $\theta_{1}$ and $\theta_{3}$ (triangulation rate) are growing consistently with the growing distance between consignor

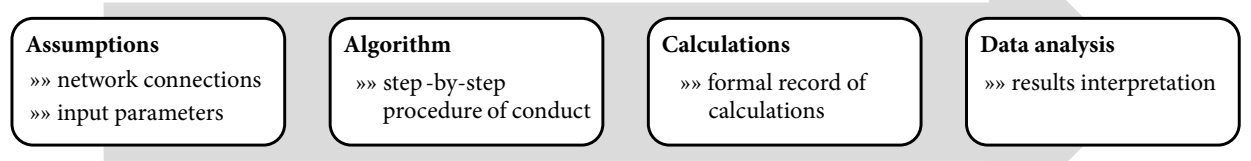

Figure 2. Scheme of research algorithm 
and consignee. In extreme cases - for example when the distance between consignor and consignee is sufficiently high, the level of triangulation is equal to " 1 " because carriers go to extra lengths to avoid arranging empty courses.

\subsection{Input data parameterization}

For the purposes of methodological research and formulation of decision-making processes, input data parameterization has been prepared and posted in Table 1. This input data parameterization will help to identify the intermodal transport network.

\subsection{The EMIS method algorithm}

The EMIS method was developed for research purposes. This method allows one to estimate the amount of $\mathrm{CO}_{2}$ emitted into the atmosphere where various organizational solutions are concerned. Seven stages of this method were singled out below.

\section{Stage 1: input data parameterization}

The first step was to determine a task size - among others: number of containers and their type. It is assumed that the number of containers transported by intermodal mode $L K_{R C}$ is equivalent to the number of containers transported by road mode $L K_{D}$. Formally, it means that $L K_{R C}=L K_{D}$. A generic structure of containers handled in the current example may be determined based on the equation specified below:

$$
L K_{R C}^{r k}=L K_{R C} \cdot m_{r k}
$$

and

$$
L K_{D}^{r k}=L K_{D} \cdot m_{r k}, r k \in R K,
$$

notifications: $L K_{R C}^{r k}$ - number of containers of $r k$-type transported by intermodal mode; $L K_{D}^{r k}$ - number of containers of $r k$-type transported by road mode; $m_{r k}-$ a share of $r k$-type of containers in the total number of container in the transport task under consideration. The $m_{r k}$ value should meet the following conditions:

$$
m_{r k}=0.1
$$

and

$$
\sum_{r k \in \boldsymbol{R} \boldsymbol{K}} m_{r k}=1
$$

\begin{tabular}{|c|c|}
\hline Parameter notification & Parameter interpretation \\
\hline$A_{n}=\left\{A_{n}: n=\overline{1, N}\right\}$ & group of container shippers \\
\hline$C_{o}=\left\{C_{o}: o=\overline{1, O}\right\}$ & group of container recipients \\
\hline $\boldsymbol{P}=\{p: p=\overline{1, P}\}$ & set of the road vehicles used due to transport containers \\
\hline$K=\{k: k=\overline{1, K}\}$ & set of the rail vehicles used due to transport containers \\
\hline $\boldsymbol{R} \boldsymbol{K}=\{r k: r k=\overline{1, R K}\}$ & container collection types \\
\hline$l_{A_{n} B}^{p}$ & $\begin{array}{l}\text { a length of road connection of the } l \text { type between } A_{n} \text { type of consignor and intermodal terminal, where } \\
\text { containers are being delivered by } p \text { type of road vehicle. In this case, all length types derived from entire } \\
\text { groups of consignors can be identified as: } L=\left[l_{A_{n} B}^{p}\right]_{N \times B \times P}, l_{A_{n} B}^{p} \in R^{+}, A_{n} \in A_{n}, p \in P\end{array}$ \\
\hline$l 1_{E C_{o}}^{p}$ & $\begin{array}{l}\text { a length of road connection of the } l 1 \text { type between intermodal terminal and the } C_{o} \text { type of consignee, } \\
\text { where containers are being delivered by } p \text { type of road vehicle. In this case, all length types derived from } \\
\text { entire groups of consignee can be identified as: } L 1=\left[l 1_{E C_{o}}^{p}\right]_{E \times C_{O} \times P}, l 1_{E C_{o}}^{p} \in R^{+}, C_{o} \in C_{o}, p \in P\end{array}$ \\
\hline$l 2_{B E}^{k}$ & $\begin{array}{l}\text { a length of rail connection of the } l 2 \text { type between intermodal terminals, where containers are being } \\
\text { delivered by } k \text { type of rail vehicle; } l 2_{p t(B E)}^{k} \in R^{+}, k \in K\end{array}$ \\
\hline $13_{A_{n} C_{o}}^{p}$ & $\begin{array}{l}\text { a length of road connection of the } l 3 \text { type between } A_{n} \text { type of consignor and } C_{o} \text { type of consignee, where } \\
\text { containers are being delivered by } p \text { type of road vehicle. In this case, all types of lengths can be identified } \\
\text { as: } L 3=\left[l 3_{A_{n} C_{o}}^{p}\right]_{x_{x}}, l 3_{A_{n} C_{o}}^{p} \in R^{+}, A_{n} \in A_{n}, C_{o} \in C_{o}, p \in P\end{array}$ \\
\hline$l 4_{D A_{n}}^{p}$ & $\begin{array}{l}\text { a length of road connection of the } l 4 \text { type between pickup/drop-off point for empty containers and } A_{n} \\
\text { type of consignor, where containers are being delivered by } p \text { type of road vehicle. In this case, all types of } \\
\text { lengths can be identified as: } L 4=\left[l 4_{D A_{n}}^{p}\right]_{D \times N \times P}, l 4_{D A_{n}}^{p} \in R^{+}, A_{n} \in A_{n}, p \in P\end{array}$ \\
\hline $15_{C_{o} D}^{p}$ & $\begin{array}{l}\text { a length of road connection of the } l 5 \text { type between } C_{o} \text { type consignee and pickup/drop-off point for empty } \\
\text { containers, where containers are being delivered by } p \text { type of road vehicle. In this case, all types of lengths } \\
\text { can be identified as: } L 5=\left[l 5_{C_{o} D}^{p}\right]_{O \times D \times P}, l 5_{C_{o} D}^{p} \in R^{+}, C_{o} \in C_{o}, p \in P\end{array}$ \\
\hline
\end{tabular}

Table 1. Input data parameterization 


\section{Stage 2: coordinates of consignors and consignees generating process}

To reach research objectives, a data set was generated. This data can be treated as a reflection of the stochastic container delivery process. Using Microsoft Excel, a special program was developed, which uses input parameters provided by authors. To estimate coordinates of consignors and consignees, a required number of stochastic parameters were generated. The value of the coordinates was a function of the transport task size. A standard Microsoft Excel function known as RAND allow one to generate stochastic values from the range $(-1,1)$. New coordinates are built based on those stochastic values. It is a necessary and sufficient condition to acknowledge the process as stochastic. Operation of the data generation process can be revised for the optional numbers of variants $w$ under analysis $w \in W$. In addition, variants are different in terms of distance between intermodal terminals.

The coordinate generating process has been demonstrated below:

1) firstly, the geographical coordinates of a: "» first (begin) intermodal terminal $B_{w}\left(X_{B_{w}}, Y_{B_{w}}\right)$; "» first (target) intermodal terminal $E_{w}\left(X_{E_{w}}, Y_{E_{w}}\right)$; "» pickup/drop-off point for empty containers $D_{w}\left(X_{D_{w}}, Y_{D_{w}}\right)$ must be manually inserted into a program. It has been assumed that values of coordinates $D_{w}\left(X_{D_{w}}, Y_{D_{w}}\right)$ are constant. The remainder are not;

2) secondly, it was obligatory to determine a: "» minimal $\min R_{w}^{\min }\left(B_{w}\right)$ and maximal $\max R_{w}^{\max }$ $\left(B_{w}\right)$ radius of delivery container to the intermodal terminal;

"» minimal $\min R_{w}^{\min }\left(E_{w}\right)$ and a maximal $\max R_{w}^{\max }$ $\left(E_{w}\right)$ radius of delivery from the intermodal terminal.

It is assumed that in Central Europe $1^{\circ}$ on the map is equivalent to a distance of $73 \mathrm{~km}(111 \mathrm{~km}$ near to equator);

3) next step was to transform a physical radius of delivery onto latitude and longitude:

$$
\begin{aligned}
& \rho_{B_{w}}=\left\langle\frac{R_{w}^{\min }\left(B_{w}\right)}{73} ; \frac{R_{w}^{\max }\left(B_{w}\right)}{73}\right\rangle ; \\
& \rho_{E_{w}}=\left\langle\frac{R_{w}^{\min }\left(E_{w}\right)}{73} ; \frac{R_{w}^{\max }\left(E_{w}\right)}{73}\right\rangle ;
\end{aligned}
$$

4) for each quadrant of the coordinate system stochastic parameters $\aleph_{w}^{n}$ and $\aleph$ have been generated. Those parameters enable us to reflect the relative placement of localization of consignees and consignors from the beginning of the coordinate system where the coordinates of the intermodal terminals $B_{w}$ and $E_{w}$ are inscribed (Figure 3 ). As previously mentioned, a group of parameters are generated based on a RAND function. Values of parameters meet the following condition: $\aleph \cdot \aleph_{w}^{n} \wedge \aleph_{w}^{o} \in(-1,1)$. In addition, the parameter values take a positive value "+" or negative value "-" depending on which quadrant of the coordinate system a random consignor or consignee appears;

5) moreover, a value of the parameter $\tau_{w}^{n}$ and $\tau_{w}^{o}$ was estimated which made it possible to carry out the parameterization of consignors and consignees coordinates. Those parameters are correlated with the area of terminal $B_{w}$ and $E_{w}$. Thus the value of parameters were calculated as:

$$
\begin{aligned}
& \tau_{w}^{n}=\aleph_{w}^{n} \cdot\left(\frac{R_{w}^{\max }\left(B_{w}\right)}{73 \cdot \sqrt{2}}-\frac{R_{w}^{\min }\left(B_{w}\right)}{73 \cdot \sqrt{2}}\right)+\frac{R_{w}^{\min }\left(B_{w}\right)}{73 \cdot \sqrt{2}} ; \\
& \tau_{w}^{o}=\aleph_{w}^{o} \cdot\left(\frac{R_{w}^{\max }\left(E_{w}\right)}{73 \cdot \sqrt{2}}-\frac{R_{w}^{\min }\left(E_{w}\right)}{73 \cdot \sqrt{2}}\right)+\frac{R_{w}^{\min }\left(E_{w}\right)}{73 \cdot \sqrt{2}} ;
\end{aligned}
$$

6) the ultimate values of coordinates could be calculated from the following dependencies:

$$
\begin{aligned}
& \vee A_{n} \in \boldsymbol{A}_{\boldsymbol{n}} \\
& A_{n}^{w}\left(X_{A_{n}^{w}}, Y_{A_{n}^{w}}\right)=B_{w}\left(X_{B_{w}}+\tau_{w}^{n}, Y_{B_{w}}+\tau_{w}^{n}\right) \\
& \vee C_{o} \in C_{\boldsymbol{o}} \\
& C_{o}^{w}\left(X_{C_{o}^{w}}, Y_{C_{o}^{w}}\right)=E_{w}\left(X_{E_{w}}+\tau_{w}^{o}, Y_{E_{w}}+\tau_{w}^{o}\right) .
\end{aligned}
$$

In the current analysis, the real curvature of the road has been skipped. Authors of this paper use only vector values.

The model allows changing the distance between terminals $B_{w}$ and $E_{w}$. The model is also sensitive to the behaviour of the remaining road distances that are correlated with rail distance between terminals. This application determines the amount of $\mathrm{CO}_{2}$ emitted into the atmosphere by vehicles.

Terminals $B_{w}$ and $E_{w}$ have been inscribed into the centre of coordinate systems. Based on them, two circles have been drawn. The radius of the smaller circle is the minimum distance of delivery. The radius of the larger circle is the maximum distance of delivery. The coordinate system is inscribed in the point $B_{w}$ or $E_{w}$. The circles are divided into four parts. In each quadrant of the coordinate system, coordinates take the positive value “+” or negative value “-”. This fact could be written by equation:

$$
\begin{aligned}
& I\left(\left(+X_{A_{n}^{w}},+Y_{A_{n}^{w}}\right) \text { or }\left(+X_{C_{o}^{w}},+Y_{C_{o}^{w}}\right)\right) ; \\
& I I\left(\left(-X_{A_{n}^{w}},+Y_{A_{n}^{w}}\right) \text { or }\left(-X_{C_{o}^{w}},+Y_{C_{o}^{w}}\right)\right) ; \\
& I I I\left(\left(-X_{A_{n}^{w}},-Y_{A_{n}^{w}}\right) \text { or }\left(-X_{C_{o}^{w}},-Y_{C_{o}^{w}}\right)\right) ; \\
& I V\left(\left(+X_{A_{n}^{w}},-Y_{A_{n}^{w}}\right) \text { or }\left(+X_{C_{o}^{w}},-Y_{C_{o}^{w}}\right)\right) .
\end{aligned}
$$

It was demonstrated that the placement of coordinates of consignors and consignees took a normal distribution. 


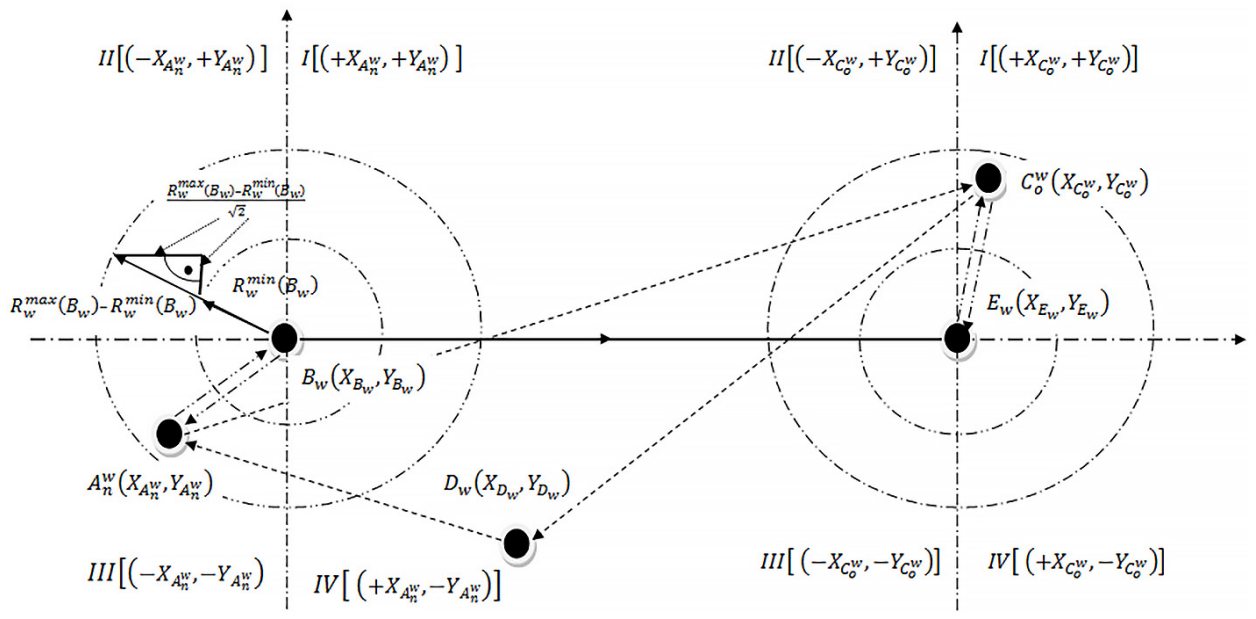

Figure 3. The distribution of consignors and consignees - graphic model

The truth is that the probability of finding a consignor or consignee in the optional quadrant of the coordinate system is equivalent to 0.25 .

\section{Stage 3: estimating the number of handlings in intermodal and road transport}

When presented with a transport task volume, and knowing the structure of the type of containers, it is possible to calculate the number of transport cycles necessary, by each transport mode, to execute an entire transport plan. The number of cycles can vary depending on; type of transport branch, capacity of the means of transport, value of triangulation factor, etc. In the given example, the total number of transshipments in a specific transport relation has been calculated thanks to the following equations:

"» number of road transport handlings

$$
\begin{aligned}
& L O_{A_{\boldsymbol{n}} B_{w}}^{r v}=\sum_{p \in \boldsymbol{P}}\left(2-q_{p}^{r v}\right) \cdot \sum_{r k \in \boldsymbol{R} \boldsymbol{K}}\left(\frac{L K_{r k}}{P S_{r k}^{p}}+\frac{L K_{r k}}{P S_{r k}^{p}} \cdot \beta_{2}\right) ; \\
& L O_{E_{w} C_{\boldsymbol{o}}}^{r v}=\sum_{p \in \boldsymbol{P}}\left(2-q_{p}^{r v}\right) \cdot \sum_{r k \in \boldsymbol{R} \boldsymbol{K}}\left(\frac{L K_{r k}}{P S_{r k}^{p}}+\frac{L K_{r k}}{P S_{r k}^{p}} \cdot \beta_{4}\right) ; \\
& L O_{D A_{n}}^{r v}=\sum_{p \in \boldsymbol{P}}\left(2-q_{p}^{r v}\right) \cdot \sum_{r k \in \boldsymbol{R} \boldsymbol{K}}\left(\frac{L K_{r k}}{P S_{r k}^{p}} \cdot \theta_{2}\right) ; \\
& L O_{A_{n} C_{\boldsymbol{o}}}^{r v}=\sum_{p \in \boldsymbol{P}}\left(2-q_{p}^{r v}\right) \cdot \sum_{r k \in \boldsymbol{R} \boldsymbol{K}}\left(\frac{L K_{r k}}{P S_{r k}^{p}}\right) ; \\
& L O_{\boldsymbol{C}_{\boldsymbol{o}} D}^{r v}=\sum_{p \in \boldsymbol{P}}\left(2-q_{p}^{r v}\right) \cdot \sum_{r k \in \boldsymbol{R} \boldsymbol{K}}\left(\frac{L K_{r k}}{P S_{r k}^{p}} \cdot \theta_{4}\right),
\end{aligned}
$$

notifications: $q_{p}^{r v}$ - an average utilization of road vehicle of the $p$-type, $P S_{r k}^{p}$ - capacity of $p$-type road vehicle in terms of $r k$-type container;

»» number of rail transport handlings

$$
L O_{B_{w} E_{w}}^{r a i}=\sum_{k \in \boldsymbol{K}}\left(2-q_{k}^{r a i}\right) \times \sum_{r k \in \boldsymbol{R} \boldsymbol{K}}\left(\frac{L K_{r k}}{P K_{r k}^{k}}\right),
$$

notifications: $\tilde{q_{k}}$ - an average utilization of rail vehicle of the $k$-type, $P K_{r k}^{k}$ - capacity of a rail vehicle of the $k$-type in terms of $r k$-type container.

Vehicle utilization is an important gauge that tells us about transport effectiveness. This factor is determined by variables such as gross container weight, or organizational effectiveness of the container allotment on the wagon or semi-trailer.

\section{Stage 4: estimating the total amount of fuel that is needed to execute the entire transport task}

A $\mathrm{CO}_{2}$ amount that is emitted into the atmosphere by the specific vehicles can be perceived as a derivative of the fuel that is consumed in the given transport cycle. The total amount of fuel needed to execute a considered transport task is equal:

"» in the intermodal transport:

$$
\begin{aligned}
& S_{w}^{c o m}=\sum_{A_{n} \in A_{\boldsymbol{n}}} \sum_{p \in \boldsymbol{P}}\left(\left(L O_{A_{\boldsymbol{n}} B_{w}}^{r v} \cdot \delta_{A_{n}}^{r}\right) \cdot l_{A_{n} B_{w}}^{p}\right) \cdot \frac{\mu_{p}^{r v}}{100}+ \\
& \sum_{k \in \boldsymbol{K}}\left(\left(L O_{B_{w} E_{w}}^{r a i} \cdot \gamma_{k}^{r a i}\right) \cdot l 2_{B_{w} E_{w}}^{k}\right) \cdot \frac{\mu_{k}^{r a i}}{100}+ \\
& \sum_{C_{o} \in C_{\boldsymbol{o}}} \sum_{p \in \boldsymbol{P}}\left(\left(L O_{E_{w} C_{\boldsymbol{o}}}^{r v} \cdot \delta_{C_{o}}^{r v}\right) \cdot l l_{E_{w} C_{o}}^{p}\right) \cdot \frac{\mu_{p}^{r v}}{100}[\mathrm{~L} / \mathrm{task}] ;(15)
\end{aligned}
$$

»» in the road transport:

$$
\begin{aligned}
& S I P_{w}^{r o a}=\sum_{A_{n} \in A_{n}} \sum_{p \in \boldsymbol{P}}\left(\left(L O_{D A_{n}}^{r v} \cdot \delta 2_{A_{n}}^{r v}\right) \cdot l 4_{D A_{n}}^{p}\right) \cdot \frac{\mu_{p}^{r v}}{100}+ \\
& \sum_{A_{n} \in A_{n}} \sum_{p \in \boldsymbol{P}}\left(\left(L O_{A_{n} C_{\boldsymbol{o}}}^{r v} \cdot \delta 3_{A_{n}}^{r v}\right) \cdot l 3_{A_{n} C_{o}}^{p}\right) \cdot \frac{\mu_{p}^{r v}}{100}+ \\
& \sum_{C_{o} \in \boldsymbol{C}_{\boldsymbol{o}}} \sum_{p \in \boldsymbol{P}}\left(\left(L O_{C_{\boldsymbol{o}} D}^{r v} \cdot \delta 4_{C_{o}}^{r v}\right) \cdot l 5_{C_{o} D}^{p}\right) \cdot \frac{\mu_{p}^{r v}}{100}[\mathrm{~L} / \text { task }] ;(16)
\end{aligned}
$$

notifications: $\delta_{A}^{r v}-$ a share of transport handlings carried from $A_{n}$-type of consignor among all transport handlings in the road transport carried from entire consignors to terminal $B_{w} ; \mu_{p}^{r v}$ - an average fuel consumption of road vehicle of the $p$-type a share of the transport handlings 
carried by $k$-type of rail vehicle among the total transport handlings realized between intermodal terminals $B_{w}$ and $E_{w} ; \mu_{k}-$ an average fuel consumption of $k$-type of the road vehicle; $\delta 1_{C_{o}}^{r v}$ - a share of transport handlings carried from terminal $E_{w}^{o}$ to $C_{o}$-type of consignee among the total road transport handlings carried from many consignees; $\delta 2_{A_{n}}^{r v}$ - a share of transport handlings carried from pickup/drop-off point to $A_{n}$-type of consignor among the total road transport handlings carried to many consignors; $\delta 3_{A_{n}}^{r v}$ - a share of transport handlings carried from $A_{n}$-type of consignor among the total transport handlings carried from many shippers to $C_{o}$-type of consignee; $\delta 4_{C_{o}}^{r v}$ - a share of transport handlings from $C_{o}$-type of consignee to empty container drop-off point among the total transport handlings carried by road transport from many consignees to container drop-off point.

\section{Stage 5: estimating $\mathrm{CO} 2$ amount emitted into the atmosphere}

At present, diesel fuel still remains the most popular fuel used to propel trucks and locomotives. For example in Poland, in 2017, nearly $40 \%$ more locomotives were propelled by diesel fuel than by electric power. Accordingly, $\mathrm{CO}_{2}$ estimation processes have been carried out only for diesel vehicles.

Estimation of $\mathrm{CO}_{2}$ emission process:

1) a demonstrated model is based on the theory of the organic fuel combustion. In a simple form, it has been assumed that organic hydrocarbon (which composition is similar to diesel) is combusted with oxygen $\mathrm{O}_{2}$ and $\mathrm{N}_{2}$. While by products of the incineration are: $\mathrm{CO}_{2}, \mathrm{H}_{2} \mathrm{O}$ and $\mathrm{N}_{2}$. In this regard, the formula of the fuel combustion process has the following form:

$$
\begin{aligned}
& w s_{1}\left(\mathrm{C}_{\mathrm{v}} \mathrm{H}_{\mathrm{z}}\right)+w s_{2}\left(\mathrm{O}_{2}+3.76 \cdot \mathrm{N}_{2}\right) \Rightarrow \\
& w s_{3}\left(\mathrm{CO}_{2}\right)+w s_{4}\left(\mathrm{H}_{2} \mathrm{O}\right)+w s_{5}\left(\mathrm{~N}_{2}\right),
\end{aligned}
$$

where: $w s_{1} \ldots w s_{5}, v, z-$ a group of stoichiometric coefficients related to a type of hydrocarbon;

2) the second step is to determine the total atomic mass of the first substrate and the first product of incineration based on the Equation (17). Atomic masses of carbon, hydrogen and oxygen were read from the periodic table. The total atomic mass of the compounds marked as $P S_{1}$ - the first substrate and $P S_{2}$ - the first product of the fuel incineration:

$P S_{1}=\operatorname{mol} w s_{1}\left(\mathrm{C}_{\mathrm{v}} \mathrm{H}_{\mathrm{z}}\right)=$

$w s_{1}(v \cdot 12+z \cdot 1)$ [amu];

$P S_{2}=\operatorname{mol} w s_{3}\left(\mathrm{CO}_{2}\right)=$

$w s_{3}(2 \cdot 12+16)[\mathrm{amu}]$.

In favourable conditions, the atomic mass of the first substratum $P S_{1}$ should be proportional to the mass of the first product $P S_{2}$ :

$P S_{2}=f\left(P S_{1}\right)[\mathrm{amu}] ;$
3) finally, the total $\mathrm{CO}_{2}$ emission can be calculated for the given parameters. For intermodal transport $E S_{w}^{\sim}$ and road transport $E S_{w}^{\sim}$ amount of $\mathrm{CO}_{2}$ will be equal to:

$$
\begin{aligned}
& E S_{w}^{c o m}=\varphi \cdot\left(\frac{P S_{2}}{P S_{1}} \cdot S^{c} P_{w}^{c o m}\right)\left[\mathrm{kg} \mathrm{CO}_{2}\right] ; \\
& E S_{w}^{r o a}=\varphi \cdot\left(\frac{P S_{2}}{P S_{1}} \cdot S_{P_{w}}^{r o a}\right)\left[\mathrm{kg} \mathrm{CO}_{2}\right],
\end{aligned}
$$

where: $\varphi$ - a fuel density.

Stage 6: estimating a boundary value where $\mathrm{CO}_{2}$ emission from intermodal transport is equal to emission from road transport

In terms of the ecological aspect, intermodal transport is more competitive than road transport when the total amount of $\mathrm{CO}_{2}$ produced by road transport eclipses total $\mathrm{CO}_{2}$ emission issued by intermodal transport. Functions of $\mathrm{CO}_{2}$ emission intersection indicate the exact minimum efficiency limit of intermodal transport in relation to road transport.

$$
\begin{aligned}
& y_{1 w}^{c o m}=a_{1} \cdot l 2_{B_{w} E_{w}}^{k}+b_{1} ; \\
& y_{{ }_{w}}^{\text {roa }}=a \cdot l 2_{B_{w} E_{w}}^{k}+b,
\end{aligned}
$$

where:

$$
\begin{aligned}
& a_{1}=\frac{\sum_{w \in W}\left(l 2_{B_{w} E_{w}}^{k}-\overline{l 2_{B E}^{k}}\right) \cdot \sum_{w \in W}\left(E S_{w}^{c o m}-\overline{E S^{c o m}}\right)}{\left(l 2_{B_{w} E_{w}}^{k}-\overline{l 2_{B E}^{k}}\right)^{2}} ; \\
& a_{2}=\frac{\sum_{w \in W}\left(l 2_{B_{w} E_{w}}^{k}-\overline{l 2_{B E}^{k}}\right) \cdot \sum_{w \in W}\left(E S_{w}^{r o a}-\overline{E S^{r o a}}\right)}{\left(l 2_{B_{w} E_{w}}^{k}-\overline{l 2_{B E}^{k}}\right)^{2}} ; \\
& b_{1}=\overline{E S^{c o m}}-a_{1} \cdot \overline{l 2^{k}} \\
& b_{2}=\overline{E S^{r o a}}-a_{2} \cdot \overline{l 2^{k}}
\end{aligned}
$$

notifications: $\overline{E S^{c o m}}$ - an average $\mathrm{CO}_{2}$ emission for combined transport; $\overline{E^{\prime r o a}}$ - an average $\mathrm{CO}_{2}$ emission for combined transport; $\overline{l 2_{B E}^{k}}$ - an average distance between intermodal terminals.

In the current case, the length of railway distance between terminals has a crucial meaning because these distances directly affect the $\mathrm{CO}_{2}$ emission curve. In doing so, the solution of $\mathrm{CO}_{2}$ linear function intersection meets the following dependence:

$$
\operatorname{ES}^{\mathrm{com}}\left(l 2_{B E}^{k}\right)=E S^{r o a}\left(l 3_{A_{n} C_{o}}^{p}\right) .
$$

\section{Stage 7: estimating $\mathrm{CO}_{2}$ emission}

\section{per gross-tone-kilometre}

The last step of the aforementioned method was to estimate amount of $\mathrm{CO}_{2}$ emitted by combined transport $\rho_{w}^{\tilde{w}}$ 
and road transport $\rho_{w}^{r o a}\left[\mathrm{~g} \mathrm{CO}_{2} / \mathrm{g}-\mathrm{t}-\mathrm{km}\right]$. It could be done based on the: mass of vehicles their characteristic and $\mathrm{CO}_{2}$ amount emitted by road and rail transport. Due to this purpose, the following equations have been used:

$$
\begin{aligned}
\rho_{w}^{c o m} & =\frac{E S_{w}^{c o m}}{B T K_{w}^{c o m}}\left[\mathrm{~g} \mathrm{CO}_{2} / \mathrm{g}-\mathrm{t}-\mathrm{km}\right] ; \\
\rho_{w}^{r o a} & =\frac{E S_{w}^{r o a}}{B T D_{w}^{r o a}}\left[\mathrm{~g} \mathrm{CO}_{2} / \mathrm{g}-\mathrm{t}-\mathrm{km}\right],
\end{aligned}
$$

where:

$$
\begin{aligned}
& B T K_{w}^{c o m}=\omega_{a v g}^{r o a} \cdot\left(\sum_{A_{n} \in A_{n}} \sum_{p \in \boldsymbol{P}}\left(L O_{A_{n} B_{w}}^{r v} \cdot \delta_{A_{n}}^{r v}\right)+\right. \\
& \sum_{C_{o} \in \boldsymbol{C}_{\boldsymbol{o}}} \sum_{p \in \boldsymbol{P}}\left(L O_{E_{w} C_{\boldsymbol{o}}}^{r v} \cdot \delta 1_{C_{o}}^{r v}\right) \cdot l 1_{E_{w} C_{o}}^{p}+ \\
& \left.\omega_{\text {avg }}^{r a i} \cdot \sum_{k \in \boldsymbol{K}}\left(L O_{B_{w} E_{w}}^{r a i} \cdot \gamma_{k}^{r a i}\right) \cdot l 2_{B_{w} E_{w}}^{k}\right) ; \\
& B D T_{w}^{r o a}=\omega_{a v g}^{r o a} \cdot\left(\sum_{A_{n} \in A_{n}} \sum_{p \in \boldsymbol{P}}\left(L O_{D A_{n}}^{r v} \cdot \delta 2_{A_{n}}^{r v} \cdot l 4_{D A_{n}}^{p}\right)+\right. \\
& \sum_{A_{n} \in A_{n}} \sum_{p \in \boldsymbol{P}}\left(L O_{A_{n} C_{\boldsymbol{o}}}^{r v} \cdot \delta 3_{A_{n}}^{r v} \cdot l 3_{A_{n} C_{o}}^{p}\right)+ \\
& \left.\sum_{C_{o} \in C_{\boldsymbol{o}}} \sum_{p \in \boldsymbol{P}}\left(L O_{\boldsymbol{C}_{\boldsymbol{o}} D}^{r v} \cdot \delta 4_{C_{o}}^{r v} \cdot l 5_{C_{o} D}^{p}\right)\right)
\end{aligned}
$$

notifications: $\omega_{a v g}^{r o a}$ - an average gross weight of road vehicle; $\omega_{\text {avg }}^{r a i}$ - train average gross weight.

\section{Case study}

Due to the EMIS method, multiple experimental calculations have been executed. This step enables to work out general conclusions.

In the current papers, the intermodal system handles only $20^{\prime}$ and $40^{\prime}$ containers. Table shows a basic input data for the analysed model.

Most parameters result from empiric observations. For instance, the average intermodal train length in Europe is equal to $600 \mathrm{~m}$. On such length, a train may be loaded either with 44 units of $40^{\prime}$ containers or 88 units of $20^{\prime}$ containers. We assumed that the average unit's weight amounts to $15 \mathrm{t}$ (with standard deviation $\pm 5 \mathrm{t}$ ). When total cargo weight and wagon tare is summed, the train can weigh between $1200 \ldots 1800 \mathrm{t}$. For scientific purposes it has been assumed that the train weighs $1300 \mathrm{t}$. Accordingly, the same assumptions were made with truck weights. The terminal delivery/pickup radius was estimated consistently with distances characteristic for intermodal transport (EC 1992). The triangulation level refers to the level and quality of transport organization within the considered trucking company. Very often, a better organization means higher triangulation level. To increase the triangulation level, a trucking enterprise can, for example, send an announcement about truck availability to freight exchange institutions. Truck and locomotive fuel consumption can
Table 2. Input data for analysis

\begin{tabular}{|l|l|c|}
\hline \multicolumn{1}{|c|}{ Parameter } & \multicolumn{1}{|c|}{$\begin{array}{c}\text { Parameter } \\
\text { value }\end{array}$} & $\begin{array}{c}\text { Parameter } \\
\text { unit }\end{array}$ \\
\hline$L K_{R C}=L K_{D}$ & 120 & unit \\
\hline$m_{1}, m_{2}$ & $0.5,0.5$ & - \\
\hline$\mu_{p}^{r v}, \mu_{k}^{\text {rai }}$ & 35,800 & $\mathrm{~L}$ \\
\hline$R_{w}^{\min }\left(B_{w}\right), R_{w}^{\max }\left(B_{w}\right)$ & 50,150 & $\mathrm{~km}$ \\
\hline$R_{w}^{\min }\left(E_{w}\right), R_{w}^{\max }\left(E_{w}\right)$ & 50,150 & $\mathrm{~km}$ \\
\hline$P S_{1}^{1}, P S_{2}^{1}$ & 2,1 & unit \\
\hline$P K_{1}^{1}, P K_{2}^{1}$ & 88,44 & unit \\
\hline$q_{p}^{r v}, q_{k}^{r a i}$ & 100,100 & $\%$ \\
\hline$\beta_{1}, \beta_{3}$ & $0.7,0.7$ & - \\
\hline$\theta_{1}, \theta_{3}$ & $0.3,0.5$ & - \\
\hline$w s_{1}, w s_{2}, w s_{3}, w s_{4}, w s_{5}$ & $1.0,24.5,16.0,17.0,92.12$ & $\mathrm{amu}$ \\
\hline$v, z$ & $16.0,34.0$ & $\mathrm{amu}$ \\
\hline$\omega_{\text {avg }}^{\text {ra }}, \omega_{\text {avg }}^{\text {rai }}$ & $20.0,1300$ & $\mathrm{t}$ \\
\hline
\end{tabular}

be found in the vehicle card provided by the producer. Utilization of the train loading space should have quite high value due to expensive rates in rail transportation. Thus, we assumed this ratio within the range 0.5...1.0. Hydrocarbon's stoichiometric coefficients were arbitrarily adopted based on literature review (Speight 2011, 2020; $\mathrm{Xu}$ et al. 2014).

Using the EMIS method, a simulation test has been arranged. For the inserted parameters, it was possible to estimate the amount of $\mathrm{CO}_{2}$ emitted into the atmosphere. In addition, structural parameters were also determined based on (Equations (23)-(26)). Making it possible to calculate the $\mathrm{CO}_{2}$ amount for the optional distance of rail transport. Thus, linear functions of $\mathrm{CO}_{2}$ emissions take the following form:

$$
y_{1 w}^{c o m}=46.3 \cdot l 2_{B_{w} E_{w}}^{k}+27398
$$

as well as:

$$
y_{2 w}^{r o a}=113.8 \cdot l 2_{B_{w} E_{w}}^{k}+20671 .
$$

Based on these calculations, it is evident that in terms of $\mathrm{CO}_{2}$ emission, a minimal efficiency limit of intermodal transport in relation to road transport is equal to around $93 \mathrm{~km}$. Results of simulation have been posted in Table 3.

Figure 4 shows the total weight of $\mathrm{CO}_{2}$ emitted into the atmosphere as a function of rail distance between terminals and average $\mathrm{CO}_{2}$ emission (calculated as $\mathrm{g}_{2} \mathrm{CO}_{2} /$ $\mathrm{g}-\mathrm{t}-\mathrm{km}$ ) in the road and intermodal transport.

In terms of $\mathrm{CO}_{2}$ emission, when the limit of $93 \mathrm{~km}$ is being transcended, combined transport becomes more favourable for the environment, than road transport. In the case of intermodal transport, when the distance reaches $1200 \mathrm{~km}$, the $\mathrm{CO}_{2}$ emission is lower by $74273 \mathrm{~kg}$. This means that total emission is lower by $47.2 \%$ compared to road transport. On the other hand, the average $\mathrm{CO}_{2}$ emis- 
sion coming from combined transport is lower by 24.3 $\mathrm{g} \mathrm{CO}_{2} / \mathrm{g}$-t-km, which comprises an even lower emission of $52.6 \%$ over road transport. More detailed dependencies have been shown in Figure 5. The charts demonstrate the difference in the total $\mathrm{CO}_{2}$ emission and the difference in the average $\mathrm{CO}_{2}$ emission counted per $\mathrm{g} \mathrm{CO}_{2} / \mathrm{g}$-t-km as a function of distance.

Based on the provided analysis, it can be said to some extent, that the difference of $\mathrm{CO}_{2}$ emission is more advantageous for road transport than for combined transport. Specifically, the $\mathrm{CO}_{2}$ emission is lower by $12.7 \%$ for combined transport over road transport (Figure 5).

In further consideration, only triangulation level im- pact on carbon emission was tested. Other parameters remained the same as in Table 2. Results of $\mathrm{CO}_{2}$ emission for intermodal and road transport in relation to triangulation level, are shown in Table 4.

The charts show regression of $\mathrm{CO}_{2}$ emission, along with an increment of triangulation value for intermodal transport and road transport (Figure 6).

The last step was determining a carbon emission in relation to changeable value of the utilization of the train loading space and constant triangulation level $\beta_{1 / 2}=0.75$ for intermodal transport (Table 5).

Dependencies resulting from the Table 4 , are presented in Figure 7.

Table 3. Results of simulation

\begin{tabular}{|c|c|c|c|c|c|}
\hline \multirow{2}{*}{ Variant No } & \multirow{2}{*}{$\begin{array}{l}\text { Rail distance } \\
{[\mathrm{km}]}\end{array}$} & \multicolumn{2}{|c|}{ Total fuel consumption [L] } & \multicolumn{2}{|c|}{ Total $\mathrm{CO}_{2}$ amount $\left[\mathrm{kg} \mathrm{CO} \mathrm{CO}_{2}\right]$} \\
\hline & & combined & road & combined & road \\
\hline 1 & 50 & 11203 & 14820 & 29713 & 26361 \\
\hline 2 & 100 & 12060 & 15887 & 32028 & 32051 \\
\hline 3 & 200 & 13919 & 16976 & 36658 & 43431 \\
\hline 4 & 400 & 17346 & 20240 & 45918 & 66191 \\
\hline 5 & 800 & 24269 & 39881 & 64438 & 111711 \\
\hline 6 & 1200 & 31386 & 62101 & 82958 & 157231 \\
\hline
\end{tabular}
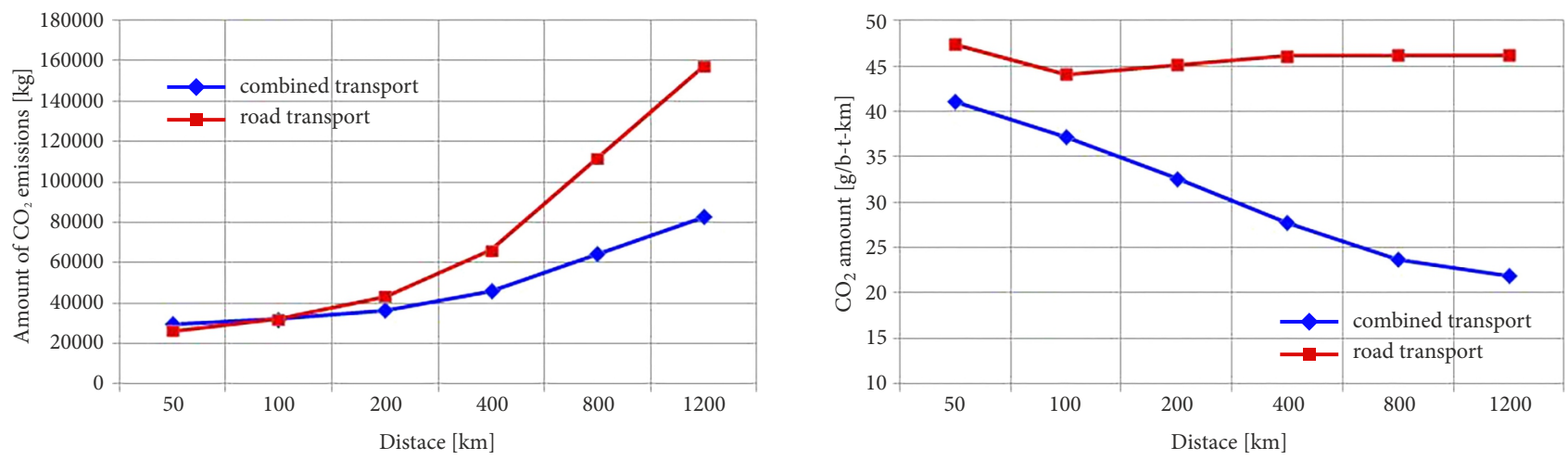

Figure 4. Total $\mathrm{CO}_{2}$ emission as a function of rail distance and an average $\mathrm{CO}_{2}$ emission in the road and intermodal transport
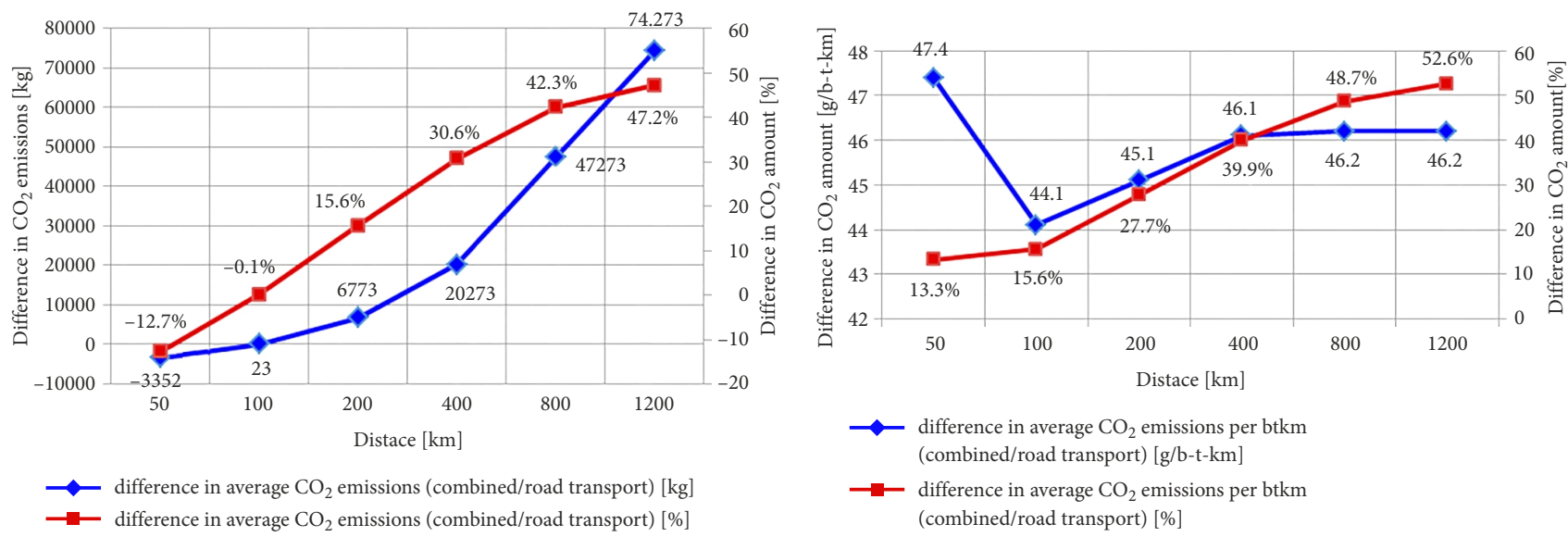

$\neg$ difference in average $\mathrm{CO}_{2}$ emissions (combined/road transport) $[\mathrm{kg}]$

$\longrightarrow$ difference in average $\mathrm{CO}_{2}$ emissions (combined/road transport) [\%]

Figure 5. Differences in the $\mathrm{CO}_{2}$ emission 
Table 4. Carbon emission in relation to triangulation value

\begin{tabular}{|c|c|c|c|c|c|c|c|c|c|c|c|}
\hline \multirow{2}{*}{$\begin{array}{c}\text { Variant } \\
\text { No }\end{array}$} & $\begin{array}{c}\text { Distance } \\
{[\mathrm{km}]}\end{array}$ & \multicolumn{10}{|c|}{ Total $\mathrm{CO}_{2}$ amount $\left[\mathrm{kg} \mathrm{CO}_{2}\right]$} \\
\cline { 3 - 13 } & $\beta_{1 / 2}=0$ & $\beta_{1 / 2}=0.25$ & $\beta_{1 / 2}=0.5$ & $\beta_{1 / 2}=0.75$ & $\beta_{1 / 2}=1$ & $\theta_{1 / 2}=0$ & $\theta_{1 / 2}=0.25$ & $\theta_{1 / 2}=0.5$ & $\theta_{1 / 2}=0.75$ & $\theta_{1 / 2}=1$ \\
\hline 1 & 50 & 47064 & 41439 & 36800 & 31177 & 25965 & 63067 & 51586 & 37249 & 25750 & 13425 \\
\hline 2 & 100 & 51156 & 46461 & 41186 & 36231 & 30182 & 62076 & 53402 & 40628 & 31127 & 19131 \\
\hline 3 & 200 & 61174 & 55450 & 50371 & 44768 & 39383 & 70986 & 61126 & 54030 & 43063 & 32543 \\
\hline 4 & 400 & 78279 & 74090 & 68461 & 62973 & 57825 & 135155 & 118650 & 102626 & 83212 & 67011 \\
\hline 5 & 800 & 97536 & 93002 & 86889 & 81551 & 76709 & 199043 & 170477 & 147256 & 122672 & 98561 \\
\hline 6 & 1200 & 47064 & 41439 & 36800 & 31177 & 2965 & 63067 & 51586 & 37249 & 25750 & 13425 \\
\hline
\end{tabular}
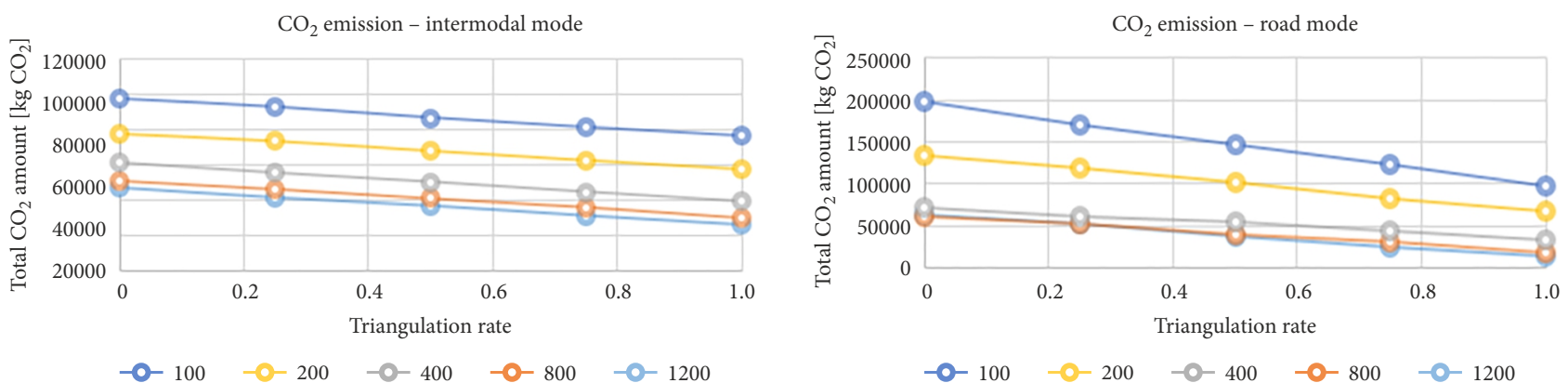

Figure 6. Regression of $\mathrm{CO}_{2}$ emission in relation to triangulation value

Table 5. Carbon emission in relation to changeable train utilization and constant triangulation level

\begin{tabular}{|c|c|c|c|c|}
\hline \multirow{2}{*}{$\begin{array}{c}\text { Variant } \\
\text { No }\end{array}$} & \multirow{2}{*}{$\begin{array}{c}\text { Distance } \\
{[\mathrm{km}]}\end{array}$} & \multicolumn{3}{|c|}{ Total $\mathrm{CO}_{2}$ amount $\left[\mathrm{kg} \mathrm{CO}_{2}\right]$} \\
\cline { 3 - 5 } & & $q_{k}^{r a i}=0.5$ & $q_{k}^{r a i}=0.75$ & $q_{k}^{r a i}=1$ \\
\hline 1 & 50 & 47064 & 31177 & 25965 \\
\hline 2 & 100 & 51156 & 36231 & 30182 \\
\hline 3 & 200 & 61174 & 44768 & 39383 \\
\hline 4 & 400 & 78279 & 62973 & 57825 \\
\hline 5 & 800 & 97536 & 81551 & 76709 \\
\hline 6 & 1200 & 47064 & 31177 & 25965 \\
\hline
\end{tabular}

$\mathrm{CO}_{2}$ emission - intermodal mode

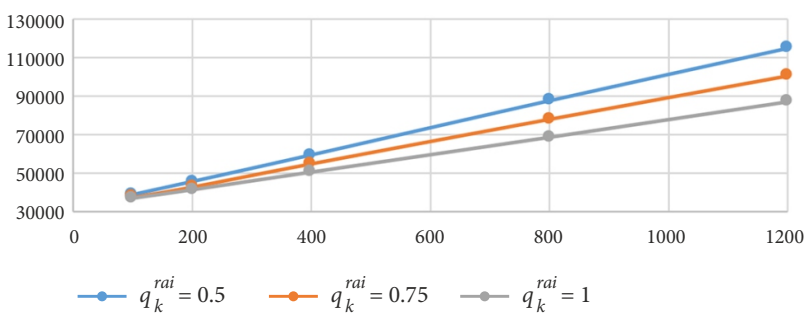

Figure 7. Increment of carbon emission in relation to train utilization

\section{Discussion of results and conclusions}

Based on the EMIS method, an innovative attitude to the analysis of $\mathrm{CO}_{2}$ emission has been presented. The EMIS method is related to the theory of organic fuel combustion with oxygen. The chemical formula of hydrocarbon fuel, whose consistency is similar to diesel fuel, was used in order to calculate the $\mathrm{CO}_{2}$ emission.
When the considered criteria is $\mathrm{CO}_{2}$ emission, this research showed how to compare two transport container organizational solutions, in terms of their impact on the natural habitat. The given method allows the possibility to prepare a model of a linear regression function, which can be useful to analyse $\mathrm{CO}_{2}$ emission levels as a function of transport distance. The model revealed that a distance of $93 \mathrm{~km}$ was a lower limit where emission from the road transport exceeds emission from intermodal transport. It turned out that emission calculated as $\mathrm{g} \mathrm{CO}_{2} / \mathrm{g}$-t $-\mathrm{km}$ decreases as rail distance increases. In the road branch, the value of indicator $\rho_{w}^{r o a}$ is much higher. It also has a relatively constant value. Meaning that a distance does not have an effect on $\mathrm{CO}_{2}$ emission level. In reference to intermodal transport, the average $\mathrm{CO}_{2}$ emission is between $22 \ldots .43 \mathrm{~g} \mathrm{CO}_{2} / \mathrm{g}$-t- $\mathrm{km}$. In the case of the road transport $44 \ldots 47.5 \mathrm{~g} \mathrm{CO}_{2} / \mathrm{g}-\mathrm{t}-\mathrm{km}$, where characteristics are almost regular.

A very well known fact is that intermodal transport with rail mode usage is not economic on short-distances. It also turns out, that intermodal transport is not effective on short-distances in terms of the ecology aspect, and plays an increasing key role in the green supply chain. Accordingly, in Figure 6 we can see, that along with an increment of triangulation value, carbon emission has regressively declined. For travelled distances in intermodal mode, when the average triangulation value was equal to zero, average $\mathrm{CO}_{2}$ emission fluctuated around $47 \ldots 100 \mathrm{t}$. When triangulation level reached a value equal to 0.5 then it was between $41 \ldots 86 \mathrm{t}$ and when it amounted to $1-$ only $30 \ldots 76$ t. On the other hand, when only road transport was considered, carbon emission was, respectively $-70 \ldots 200,54 \ldots 176$ and $13 \ldots 98 \mathrm{t}$. The most inter- 
esting distance in terms of carbon emission, was $100 \mathrm{~km}$. In this case, total carbon emission achieved a level of only $13 \mathrm{t}$. This means, that the process of triangulation is effective even on short-distances.

The last examined factor was utilization of train loading space. On short-distances, there is no difference whether utilization of train space is equal to 50,75 or even $100 \%$ because carbon emission is constant and oscillates around $36 \ldots 37 \mathrm{t}$. However, when a distance of $800 \mathrm{~km}$ is reached then carbon emission ranges from $68 \ldots 88 \mathrm{t}$ of $\mathrm{CO}_{2}$ for train utilization equal to $50,78 \mathrm{t}$ for $75 \%$ and $87 \mathrm{t}$ for full train utilization. In the case of a distance of 1200 $\mathrm{km}$, this proportion is much higher and is equal, respectively, to 87,100 and $114 \mathrm{t} \mathrm{CO}_{2}$.

These results comprise a certain warning for transport organizers. Apart from the financial cost, they should also consider environmental costs in their transport policy. As we can see, unutilized space on the intermodal train can negatively affect our natural habitat. Unfortunately, it is not always possible to completely fill trains. This may be influenced by factors, such as: an insufficient number of containers on the yard resulting from demand fluctuations, cargo weight that cause the limiting pressure surpass on wagon axle, rail-track class etc.

The level of $\mathrm{CO}_{2}$ emission was determined by stochastic locations of the consignors and consignees. On the other hand, some of the input data variables are presumed. In this regard, the transport process probably does not completely imitate the real process taking place in the real world. The following method has a significant number of both advantages and disadvantages. Advantages may include:

"») individual attitude to carbon emission. In contrast to the EMIS method, many experts use external data retrieved directly from program simulations;

"») real input parameters and detailed reconstruction of inland intermodal processes including triangulation process;

"») results concerning carbon emission coincide with another experts research (Craig et al. 2013; Heinold, Meisel 2018);

"») the novelty of this paper is the notion of carbon emission counted per gram/gross-tone-kilometre. This approach includes tare of vehicles or transport measures. Usually, specialists count carbon emission as gram/tone-kilometre of cargo. From our point of view, this is not always reliable when measuring carbon emission. Indeed, the tare of transport measures has tremendous impact on carbon emission. As an example, when two trains of the same constant cargo weight and same type of locomotive are considered, but the tare of the first train is larger than the second, it is more probable that the first train will emit more $\mathrm{CO}_{2}$.

Disadvantages of this method may include:

"» lack of consideration of the types of vehicles and wagons that have significant impact on carbon emission;
"» model stability - most parameters are presumed and constant. Variable parameters could better reflect the foundation of the presented problem;

"» only diesel propulsion is being taken into account when a lot of locomotives are electric;

"») most characteristics have linear behaviour, because the model omits vehicle dynamics - like vehicle stoppage or velocity. This can cause readers to be non-objective about the model.

Although the conducted calculations confirmed a thesis about the ecological aspect of combined transport. It is apparent that intermodal transport is a superior option in comparison to heavy-duty transport. Exceptions exist where the utilization rate of train capacity is relatively low or when the delivery/pickup radius from/to an intermodal terminal is significantly long. The given analysis can also be used to formulate the general conclusions, which have an influence on the decision-making process. In addition, these results highlight effects the transport system may have on the environment.

\section{Availability of data and material}

The datasets used and/or analysed during the current study are available from the corresponding author on reasonable request.

\section{Funding}

This work was supported by the Faculty of Transport of the Warsaw University of Technology (Poland).

\section{Author contributions}

Mariusz Brzezinski: conceptualization, methodology, software, formal analysis, investigation, writing (original draft).

Dariusz Pyza: validation, resources, data curation, writing (review and editing), visualization, supervision, project administration, funding acquisition.

\section{Disclosure statement}

The authors declare that they have no competing interests.

\section{References}

Ambroziak, T.; Gołębiowski, P.; Pyza, D.; Jacyna-Gołda, I.; Merkisz-Guranowska, A. 2013. Identification and analysis of parameters for the areas of the highest harmful exhaust emissions in the model emitransys, Journal of KONES Powertrain and Transport 20(3): 9-20.

Ambroziak, T.; Pyza, D.; Merkisz-Guranowska, A.; Jachimowski, R. 2014. Ocena wplywu transportu drogowego na degradację środowiska przy różnej strukturze pojazdów. Wydawnicza Politechniki Warszawskiej. 121. (in Polish).

Arnold, P.; Peeters, D.; Thomas, I. 2004. Modelling a rail/road intermodal transportation system, Transportation Research Part E: Logistics and Transportation Review 40(3): 255-270. https://doi.org/10.1016/j.tre.2003.08.005 
Belmecheri, F.; Cagniart, T.; Amodeo, L.; Yalaoui F.; Prins, C. 2009. Modelling and optimization of empty container reuse: a real case study, in 2009 International Conference on Computers \& Industrial Engineering, 6-9 July 2009, Troyes, France, 1106-1109. https://doi.org/10.1109/iccie.2009.5223777

Boile, M. P. 2006. Empty Intermodal Container Management. Report No FHWA-NJ-2006-005. Center for Advanced Infrastructure and Transportation (CAIT), The State University of New Jersey, US. 130 p. Available from Internet: https://cait.rutgers.edu/wp-content/uploads/2018/05/fhwa-nj-2006-005.pdf

Boysen, N.; Fliedner, M., 2010. Determining crane areas in intermodal transshipment yards: The yard partition problem, European Journal of Operational Research 204(2): 336-342. https://doi.org/10.1016/j.ejor.2009.10.031

Braekers, K.; Janssens, G. K.; Caris, A. 2009. Review on the comparison of external costs of intermodal transport and unimodal road transport, in Proceedings of the BIVEC-GIBET Transport Research Day 2009, 27 May 2009, Brussels, Belgium, 875-890.

Brzeziński, M.; Pyza, D. 2020. Designing of transshipment terminals for selected intermodal transport systems, Advances in Intelligent Systems and Computing 1032: 52-62.

https://doi.org/10.1007/978-3-030-27687-4_6

Cordeau, J.-F.; Legato, P.; Mazza, R. M.; Trunfio, R. 2015. Simulation-based optimization for housekeeping in a container transshipment terminal, Computers \& Operations Research 53: 81-95. https://doi.org/10.1016/j.cor.2014.08.001

Craig, A. J.; Blanco, E. E.; Sheff, Y. 2013. Estimating the $\mathrm{CO}_{2}$ intensity of intermodal freight transportation, Transportation Research Part D: Transport and Environment 22: 49-53. https://doi.org/10.1016/j.trd.2013.02.016

Dimoula, V.; Kehagia, F.; Tsakalidis, A. 2016. A holistic approach for estimating carbon emissions of road and rail transport systems, Aerosol and Atmospheric Chemistry 16(1): 61-68. https://doi.org/10.4209/aaqr.2015.05.0313

EC. 1992. Council Directive 92/106/EEC of 7 December 1992 on the Establishment of Common Rules for Certain Types of Combined Transport of Goods between Member States. European Communities (EC). 5 p. Available from Internet:

http://data.europa.eu/eli/dir/1992/106/oj

EC. 2015. Report from the Commission to the European Parliament and the Council on the Implementation of Regulation (EU) No 70/2012 of the European Parliament and of the Council of 18 January 2012 on Statistical Returns in Respect of the Carriage of Goods by Road. European Communities (EC). 11 p. Available from Internet: https://eur-lex.europa.eu/legal-content/EN/TXT/?uri=CELEX\%3A52015DC0017

Fan, Y.; Behdani, B.; Bloemhof-Ruwaard, J.; Zuidwijk, R. 2019. Flow consolidation in hinterland container transport: An analysis for perishable and dry cargo, Transportation Research Part E: Logistics and Transportation Review 130: 128-160. https://doi.org/10.1016/j.tre.2019.08.011

Fedtke, S.; Boysen, N. 2017. A comparison of different container sorting systems in modern rail-rail transshipment yards, Transportation Research Part C: Emerging Technologies 82: 63-87. https://doi.org/10.1016/j.trc.2017.06.012

Flodén, J.; Woxenius, J. 2017. Agility in the Swedish intermodal freight market - the effects of the withdrawal of the main provider, Research in Transportation Business \& Management 23: 21-34. https://doi.org/10.1016/j.rtbm.2017.02.010

Furió, S.; Andrés, C.; Adenso-Díaz, B.; Lozano, S. 2013. Optimization of empty container movements using street-turn: application to Valencia hinterland, Computers \& Industrial Engineering 66(4): 909-917.

https://doi.org/10.1016/j.cie.2013.09.003
García-Álvarez, A.; Pérez-Martínez, P. J.; I. González-Franco, I. 2013. Energy consumption and carbon dioxide emissions in rail and road freight transport in Spain: a case study of car carriers and bulk petrochemicals, Journal of Intelligent Transportation Systems: Technology, Planning, and Operations 17(3): 233-244. https://doi.org/10.1080/15472450.2012.719456

Grzelakowski, A. S. 2012. Rozwój transportu intermodalnego w polsce. Podstawowe uwarunkowania i wyzwania, Logistyka 5: 425-432. (in Polish).

Guo, P.; Cheng, W.; Wang, Y.; Boysen, N. 2018. Gantry crane scheduling in intermodal rail-road container terminals, International Journal of Production Research 56(16): 5419-5436. https://doi.org/10.1080/00207543.2018.1444812

Heggen, H.; Molenbruch, Y.; Caris, A.; Braekers, K. 2019. Intermodal container routing: integrating long-haul routing and local drayage decisions, Sustainability 11(6): 1634.

https://doi.org/10.3390/su11061634

Heinold, A.; Meisel, F. 2018. Emission rates of intermodal rail/ road and road-only transportation in Europe: a comprehensive simulation study, Transportation Research Part D: Transport and Environment 65: 421-437. https://doi.org/10.1016/j. trd.2018.09.003

Hjortnaes, T.; Wiegmans, B.; Negenborn, R. R.; Zuidwijk, R. A.; Klijnhout, R. 2017. Minimizing cost of empty container repositioning in port hinterlands, while taking repair operations into account, Journal of Transport Geography 58: 209-219. https://doi.org/10.1016/j.jtrangeo.2016.12.015

Jacyna, M.; Pyza, D.; Jachimowski, R. 2017. Transport intermodalny: projektowanie terminali przeładunkowych. Wydawnictwo Naukowe PWN. 282 s. (in Polish).

Jula, H.; Chassiakos, A.; Ioannou, P. 2006. Port dynamic empty container reuse, Transportation Research Part E: Logistics and Transportation Review 42(1): 43-60.

https://doi.org/10.1016/j.tre.2004.08.007

Kreutzberger, E.; Macharis, C.; Woxenius, J. 2006. Intermodal versus unimodal road freight transport: a review of comparisons of the external costs, in B. Jourquin, P. Rietveld, K. Westin (Eds.). Towards better Performing Transport Networks, 17-42.

Lebedevas, S.; Dailydka, S.; Jastremskas, V.; Rapalis, P. 2017. Research of energy efficiency and reduction of environmental pollution in freight rail transportation, Transport 32(3): 291301. https://doi.org/10.3846/16484142.2016.1230888

Li, L.; Negenborn, R. R.; De Schutter, B. 2013. A general framework for modeling intermodal transport networks, in 2013 10th IEEE International Conference on Networking, Sensing and Control (ICNSC), 10-12 April 2013, Evry, France, 579585. https://doi.org/10.1109/ICNSC.2013.6548803

Li, L.; Wang, B.; Cook, D. P. 2014. Enhancing green supply chain initiatives via empty container reuse, Transportation Research Part E: Logistics and Transportation Review 70: 190-204. https://doi.org/10.1016/j.tre.2014.06.018

Limbourg, S., Jourquin, B. 2009. Optimal rail-road container terminal locations on the European network, Transportation Research Part E: Logistics and Transportation Review 45(4): 551-563. https://doi.org/10.1016/j.tre.2008.12.003

Lin, C.-C.; Chiang, Y.-I.; Lin, S.-W. 2014. Efficient model and heuristic for the intermodal terminal location problem, Computers \& Operations Research 51: 41-51. https://doi.org/10.1016/j.cor.2014.05.004

López-Navarro, M. Á. 2014. Environmental factors and intermodal freight transportation: analysis of the decision bases in the case of Spanish motorways of the sea, Sustainability 6(3): 1544-1566. https://doi.org/10.3390/su6031544 
MTBGM. 2013. Strategia rozwoju transportu do 2020 roku (z perspektywa do 2030 roku). Ministerstwo transportu, budownictwa i gospodarki morskiej (MTBGM), Warszawa, Polska, 100 s. Available from Internet: https://www.gov.pl/ documents/905843/1047987/Strategia_Rozwoju_Transportu_do_2020_roku.pdf (in Polish).

Monios, J.; Bergqvist, R. 2017. Identifying competitive strategies for each phase of the intermodal terminal life cycle, Research in Transportation Business \& Management 23: 97-105. https://doi.org/10.1016/j.rtbm.2017.02.007

Pyza, D. 2019. Systemy przewozowe - problemy obstugi, potencjał i jego utrzymanie. Wydawnicza Politechniki Warszawskiej. 212 s. (in Polish).

Rajkovic, R.; Zrnic, N.; Bojic, S.; Stakic, Đ. 2016. Role of cargo weight and volume: minimizing costs and $\mathrm{CO}_{2}$ emissions in container transport, in Commercial Transport: Proceedings of the 2nd Interdisciplinary Conference on Production, Logistics and Traffic 2015, 21-22 July 2015, Dortmund, Germany, 159173. https://doi.org/10.1007/978-3-319-21266-1_10

Ritchie, H.; Roser, M. 2017. $\mathrm{CO}_{2}$ and Greenhouse Gas Emissions. Available from Internet: https://ourworldindata.org/co2-andother-greenhouse-gas-emissions

Saeedi, H.; Wiegmans, B.; Behdani, B.; Zuidwijk, R. 2017. Analyzing competition in intermodal freight transport networks: the market implication of business consolidation strategies, Research in Transportation Business \& Management 23: 12-20. https://doi.org/10.1016/j.rtbm.2017.02.009

Santos, B. F.; Limbourg, S.; Carreira, J. S. 2015. The impact of transport policies on railroad intermodal freight competitiveness - the case of Belgium, Transportation Research Part D: Transport and Environment 34: 230-244. https://doi.org/10.1016/j.trd.2014.10.015

Southworth, F.; Peterson, B. E. 2000. Intermodal and international freight network modeling, Transportation Research Part C: Emerging Technologies 8(1-6): 147-166. https://doi.org/10.1016/S0968-090X(00)00004-8

Speight, J. G. 2020. Hydrocarbons from crude oil, in J. G. Speight (Ed.). Handbook of Industrial Hydrocarbon Processes, 95-142. https://doi.org/10.1016/b978-0-12-809923-0.00003-5

Speight, J. G. 2011. Hydrocarbons from petroleum, in J. G. Speight (Ed.). Handbook of Industrial Hydrocarbon Processes, 85-126. https://doi.org/10.1016/b978-0-7506-8632-7.10003-9

Wiegmans, B.; Konings, R. 2015. Intermodal inland waterway transport: modelling conditions influencing its cost competitiveness, The Asian Journal of Shipping and Logistics 31(2): 273-294. https://doi.org/10.1016/j.ajsl.2015.06.006

Xu, G.-L.; Yao, C.-D.; Rutland, C. J. 2014. Simulations of diesel-methanol dual-fuel engine combustion with large eddy simulation and Reynolds-averaged Navier-Stokes model, International Journal of Engine Research 15(6): 751-769.

https://doi.org/10.1177/1468087413516119 